\section{(6) OPEN ACCESS}

\title{
Contemporaneous management of valvular heart disease and aortopathy in aircrew
}

\author{
Joanna L D'Arcy, ${ }^{1}$ Thomas Syburra, ${ }^{2}$ Norbert Guettler, ${ }^{3}$ Eddie D Davenport, ${ }^{4}$ \\ Olivier Manen, ${ }^{5}$ Gary Gray, ${ }^{6}$ Rienk Rienks, ${ }^{7}$ Dennis Bron, ${ }^{8}$ Edward D Nicol ${ }^{1}$
}

${ }^{1}$ Aviation Medicine Clinical Service, RAF Centre of Aviation Medicine, RAF Henlow, Bedfordshire, UK

${ }^{2}$ Cardiac Surgery Department, Luzerner Kantonsspital, Luzern, Switzerland

${ }^{3}$ German Air Force Center for Aerospace Medicine, Fuerstenfeldbruck, Germany

${ }^{4}$ Aeromedical Consult Service, United States Air Force School of Aerospace Medicine, WrightPatterson AFB, Ohio, USA

${ }^{5}$ Aviation Medicine Department, AeMC, Percy Military Hospital,

Clamart, France

${ }^{6}$ Canadian Forces Environmental Medical Establishment, Toronto, Ontario, Canada

'Department of Cardiology, University Medical Center Utrecht and Central Military Hospital, Utrecht, Netherlands ${ }^{8}$ Aeromedical Centre, Swiss Air Force, Dubendorf, Switzerland

Correspondence to Dr Edward D Nicol, Aviation Medicine Clinical Service, RAF Centre of Aviation Medicine, RAF Henlow, Bedfordshire, SG166DN; e.nicol@nhs.net

Received 12 April 2018 Revised 27 September 2018 Accepted 30 September 2018

D Check for updates

(C) Author(s) (or their employer(s)) 2018. Re-use permitted under CC BY-NC. No commercial re-use. See rights and permissions. Published by BMJ.

To cite: D'Arcy JL, Syburra T, Guettler $N$, et al. Heart 2019;105:s57-s63.

\section{ABSTRACT}

Valvular heart disease (VHD) is highly relevant in the aircrew population as it may limit appropriate augmentation of cardiac output in high-performance flying and predispose to arrhythmia. Aircrew with VHD require careful long-term follow-up to ensure that they can fly if it is safe and appropriate for them to do so. Anything greater than mild stenotic valve disease and/or moderate or greater regurgitation is usually associated with flight restrictions. Associated features of arrhythmia, systolic dysfunction, thromboembolism and chamber dilatation indicate additional risk and will usually require more stringent restrictions. The use of appropriate cardiac imaging, along with routine ambulatory cardiac monitoring, is mandatory in aircrew with VHD.

Aortopathy in aircrew may be found in isolation or, more commonly, associated with bicuspid aortic valve disease. Progression rates are unpredictable, but as the diameter of the vessel increases, the associated risk of dissection also increases. Restrictions on aircrew duties, particularly in the context of high-performance or solo flying, are usually required in those with progressive dilation of the aorta.

\section{INTRODUCTION}

Valvular heart disease (VHD) is relevant in the aircrew population as it may interfere with appropriate augmentation of cardiac output in high-performance flying, and predispose to arrhythmia, in all aircrew, which in turn may result in distraction or incapacitation. In aviation, the current consensus risk threshold for an acceptable level of risk of acute incapacitation is $1 \%$ per annum (for dual pilot operations), a percentage calculated using engineering principles to ensure the incidence of a fatal air accident is no greater than 1 per $10^{9}$ hours of flying. This is known as the ' $1 \%$ safety rule'.
The effect of high-performance flying on both valvular and aortic pathology is poorly understood, with little or no scientific evidence to inform risk assessment at such a low level of incapacitation. However, the potential change in haemodynamics and vascular shear stress due to sustained acceleration (increased $\mathrm{G}$ forces) mandates a pragmatic and appropriately cautious approach in aircrew, particularly given the potential flight safety risks associated with acute aortic disease. Aortic valve disease due to a bicuspid aortic valve (BAV) is the most common valvular pathology found in younger aircrew, with either associated regurgitation or stenosis, or both, while calcific aortic valve disease increases in prevalence in older aircrew, as with the general population. Valve prolapse with associated regurgitation is the most common mitral pathology encountered in aircrew. Other valve pathologies (such as rheumatic mitral stenosis, pulmonary and tricuspid valve disease) are rare in developed countries and seen relatively infrequently in aircrew. Aortic disease may be associated with BAV or be due to an inherited aetiology such as in Marfan's disease. This paper considers the screening and investigation of valvular and aortic disease, the relevant aeromedical concerns, and the recommended follow-up and aeromedical disposition of aircrew with these conditions.

\section{GENERAL AEROMEDICAL CONCERNS}

The principal aeromedical concerns are similar for all forms of VHD. They relate either to impaired tolerance to increased sustained acceleration ( $G$ forces), due to decreased ability to augment cardiac output, or to secondary arrhythmia resulting from atrial or ventricular dilatation. The lack of symptoms from VHD, until it is advanced, is of particular concern in aircrew, and it should not be assumed

${ }^{\mathrm{i}}$ Evidence-based cardiovascular risk assessment in aircrew poses significant challenges in the aviation environment as data to support decision-making at the low level of tolerable risk in aviation are rarely available from the published literature. As a result, there are discrepancies between aviation authority's recommendations in different countries, and even between licensing organisations within single countries. The NATO HFM-251 Occupational Cardiology in Military Aircrew working group is constituted of full-time aviation medicine and aviation cardiology experts who advise both their militaries and civil aviation organisations including, but not limited to, the FAA, CAA, EASA and NASA. The recommendations of this group are as a result of a 3-year working group that considered best clinical cardiovascular practice guidelines within the context of aviation medicine and risk principles. This work was conducted independently of existing national and transnational regulators, both military and civilian, but considered all available policies, in an attempt to determine best evidence-based practice in this field. The recommendations presented in this document, and associated manuscripts, is based on expert consensus opinion of the NATO group. This body of work has been produced to develop the evidence base for military aviation cardiology and to continue to update the relevant civilian aviation cardiology advice following the 1998 European Cardiology Society aviation cardiology meeting. 
that VHD will be detected on auscultation at periodic medical examination. ${ }^{23}$ The unpredictable and variable natural history of VHD, especially in its early stages, and lack of effective medical therapy are additional challenges in aircrew. Aircrew follow-up is likely to be more frequent than in the general population due to the licensing implications of any change in severity of valve lesions and its associated risk. In those who meet standard international criteria for intervention, consideration of the optimal surgical or interventional techniques (where a choice exists) for aircrew requires close liaison between the cardiovascular surgeon and aviation medical examiner (AME) from an early stage. The requirement for licensing restrictions post-cardiac surgery also requires an understanding of the effect of the aviation environment on cardiac physiology and anatomy. ${ }^{45}$ In those with arrhythmia, the risk of thromboembolic events must also be borne in mind, such as in those with atrial fibrillation (AF) secondary to VHD. For those with valve prostheses, embolic risk and arrhythmia remain an issue. ${ }^{6}$

\section{G tolerance}

Acceleration $(G)$ is a centrifugal gravitational force that in flight is usually applied to the vertical axis of the body (z-axis). If it is experienced from head to foot, it is termed $+G_{z}$; through the body in an anteroposterior direction (such as in take-off), $+G_{x}$. Aircrew may be exposed to high levels of $+G_{z}$ in manoeuvres such as pulling out of a dive or into an inside loop; certain aircraft manoeuvres, for example, an 'outside' loop or 'bunt' (pushing forward on the stick or control column), result in rapid foot-to-head $\mathrm{G}$ loading, which is termed $-\mathrm{G}_{z}$. In military aviation and aerobatics, exposure to significant $+G_{z}$ results in an exceptional strain on the cardiovascular system to maintain vital cerebral and coronary perfusion under unusual attitudes. The effect of even modest $+G_{z}$ environments on the heart is shown in table 1 . The ability to effectively counter this increased acceleration is potentially blunted in moderate to severe VHD, and individuals may become more susceptible to $G_{z}$-induced loss of consciousness. Moderate to severe valvular stenosis represents a potential restriction to cardiac output and may adversely affect $\mathrm{G}_{\mathrm{z}}$ tolerance in high-performance flight operations. In significant regurgitant valve disease, the ability to increase forward stroke volume when required may be impaired, again potentially decreasing $G_{z}$ tolerance.

$G$ exposure is also arrhythmogenic and may affect cardiac output, and this effect may be exacerbated by concomitant VHD, with the potential to cause distraction or incapacitation even at low levels of $G$ exposure $^{6}$ and mandates caution in aircrew. As a result, ambulatory cardiac monitoring is usually required for the follow-up of aircrew with VHD, even if not haemodynamically significant in a terrestrial $\left(1 \mathrm{G}_{\mathrm{z}}\right)$ environment. $\mathrm{G}$ forces from all directions may potentially have an effect on aortic disease due to altered haemodynamics and shear stress, although there is no supporting evidence on this in the clinical or aviation medicine literature.
Table 1 Effect of mild increase in sustained acceleration $\left(+G_{z}\right)$ on heart rate, stroke volume and cardiac output (adapted from DeHart RL and Davis JR, Fundamentals of aerospace medicine ${ }^{41}$ )

\begin{tabular}{llll}
\hline Parameter & $+2 \mathrm{G}_{\mathrm{z}}$ & $+3 \mathrm{G}_{\mathrm{z}}$ & $+4 \mathrm{G}_{\mathrm{z}}$ \\
\hline $\begin{array}{l}\text { Heart rate } \\
\text { (bpm) }\end{array}$ & +14 & +35 & +56 \\
$\begin{array}{l}\text { Stroke Index } \\
\left.\text { (mL/stroke } / \mathrm{m}^{2}\right)\end{array}$ & -24 & -37 & -49 \\
$\begin{array}{l}\text { Cardiac output } \\
(\% \text { change) }\end{array}$ & -7 & -18 & -22 \\
\hline
\end{tabular}

\section{Infective endocarditis}

The structural and haemodynamic abnormalities associated with VHD are known to be associated with increased risk of infective endocarditis (IE). This is of additional concern in military aircrew who may be required to operate in austere conditions. The development of IE may cause a rapid deterioration in valve function and is associated with thromboembolic phenomena, which may both be catastrophic in the aviation environment.

These general principles underpin the necessity for close follow-up of aircrew diagnosed with VHD to ensure appropriate restrictions on flight status are implemented when this becomes necessary. National and international guidelines for the follow-up of those with confirmed VHD should be considered the minimum requirement for aircrew. However, it is anticipated that they may be subject to more frequent follow-up, and more extensively investigated, for occupational reasons.

\section{APPROACHES TO SCREENING AND INVESTIGATION}

It is common that VHD remains asymptomatic until it is severe, and history may therefore be unremarkable; however, careful examination may reveal a cardiac murmur. Aortic pathology may be found in association with valve disease or identified in isolation, again often in asymptomatic individuals. Many young, fit individuals will be found to have no significant pathology, and flow murmurs are common; however, in aircrew, the finding of a murmur mandates further assessment for VHD and, if confirmed, possible associated arrhythmia; restrictions may be required while this is undertaken.

\section{INVESTIGATIONS}

The use of adequate imaging in aircrew is mandatory. As per standard clinical follow-up, it should be self-evident that the assessment of an individual with VHD, whether aircrew or not, requires consideration of the effect on overall cardiac function, in addition to the severity of the valve lesion. At each follow-up assessment, ambulatory cardiac monitoring to look for possible occult arrhythmia and assessment of cardiac chamber size, in addition to the assessment of valve severity, should be considered. The presence of arrhythmia increases the risk to aircrew and will likely result in more stringent restrictions to flight status.

\footnotetext{
${ }^{\mathrm{ii}}$ Aircrew are defined somewhat differently in civil and military aviation. NATO and ICAO delegates the definition of aircrew to national authorities. In the civilian sector, aircrew are often categorised as flight crew (pilots)/technical crew memb ers and cabin crew, with separate regulation for air traffic controllers. The military define aircrew more broadly as 'persons having duties concerned with the flying or operation of the air system, or with passengers or cargo when in flight'. From a risk perspective, professional (commercial) pilots have a higher attributable risk than private pilots and non-pilot aircrew. Controllers are considered to have an attributable risk equivalent to professional pilots. From a cardiovascular perspective, aircrew whose flying role includes repetitive exposure to high-acceleration forces $\left(G_{z}\right)$ comprise a subgroup who, due to the unique physiological stressors of this flight environment, often require specific aeromedical recommendations. A more detailed description of aircrew is available in Table 1 of the accompanying introductory paper on aviation cardiology. (Nicol ED, et al. Heart 2018;105:s3-s8. doi:10.1136/heartjnl-2018-313019).
} 


\section{Echocardiography}

As in the wider population, trans-thoracic echocardiography (TTE) permits rapid, accurate, non-invasive and relatively cheap assessment of valve structure and function in aircrew. As such, it is the first-line investigation in those with suspected VHD. ${ }^{78}$ It is also the imaging modality of choice for follow-up of aircrew with known VHD, if TTE windows permit adequate image quality. When there is poor image quality, or uncertainty about the severity of VHD on TTE (eg, due to eccentric regurgitant jets, or an angulated aortic root), additional imaging with transoesophageal echocardiography or cardiac magnetic resonance (CMR) may be required. Given the lack of sensitivity of auscultation, there is an argument for screening all aircrew with echocardiography, as well as ECG, particularly in applicants who wish to undertake high-performance flying. However, the yield of such screening is low, and potentially expensive, so therefore not usually deemed cost-effective. As a result, echocardiography is usually only undertaken if occupational concerns arise from standard periodic medical examination. Although the proximal ascending aorta, aortic arch and proximal descending aorta may be well seen on TTE, when aortic pathology is suspected, imaging of the whole thoracic aorta with CMR or CT permits more complete assessment of the aorta.

\section{Cardiac MRI and cardiovascular CT}

Cardiac MRI (CMR) can provide accurate quantitative assessment of valvular regurgitation, which can be difficult to assess by echocardiography. It may also help with prognostication. ${ }^{910}$ The assessment of pulmonary valve disease and the right heart is a strength of CMR, in addition to the assessment of the thoracic aorta without the need for intravenous contrast or exposure to ionising radiation. As outlined above, baseline imaging of the aorta should include either CT or CMR when aortopathy is suspected. When there is suspicion of significant interval change on follow-up, additional baseline imaging with either CT or CMR should also be considered. Consideration should be given to using CMR first line for the follow-up of aortic disease in aircrew to reduce longterm radiation exposure, particularly in younger aircrew.

\section{Electrocardiography and ambulatory cardiac monitoring}

A standard 12-lead ECG may provide additional information on arrhythmias or left ventricular hypertrophy $(\mathrm{LVH})$ in aircrew with suspected or confirmed VHD. LVH by 'voltage criteria' is a common finding in aircrew without VHD but may be associated with underlying aortic stenosis (with or without strain pattern) and may be associated with increasing severity of disease. ${ }^{11}$ These findings, in aircrew in whom there is a suspicion of VHD, should therefore prompt further assessment, including echocardiography. Ambulatory ECG monitoring is useful to assess for associated arrhythmia in those with VHD. The detection of paroxysmal $\mathrm{AF}$, or significant conduction disturbances, will impact on aircrew licensing decisions. In aircrew with suspected or confirmed VHD, ambulatory cardiac monitoring should be undertaken at diagnosis and periodically during follow-up. The potential for arrhythmia persists after surgery for VHD, and aircrew who have undergone valve surgery and wish to be considered for a return to flight status will also require regular assessment with ambulatory monitoring.

\section{Exercise stress testing, coronary angiography and cardiac catheterisation}

As with the general population, the use of exercise stress testing in VHD is primarily for the objective assessment of symptoms and exercise capacity. ${ }^{12}$ It often forms part of the routine screening process in military aircrew with suspected VHD and is also be used for risk stratification in civilian aviation risk assessment, especially in those with suspected or confirmed moderate or severe valve disease. ${ }^{13}$ In accordance with established guidelines, the use of invasive assessment of VHD should only be undertaken when non-invasive assessment is inconclusive or used preoperatively to assess for possible coexistent coronary artery disease. ${ }^{78}$

\begin{tabular}{|c|c|}
\hline \multicolumn{2}{|l|}{$\begin{array}{l}\text { Assessment of suspected and confirmed valvular } \\
\text { heart disease }\end{array}$} \\
\hline $\begin{array}{l}\text { In aircrew with suspected VHD, structural and } \\
\text { functional assessment with cardiac imaging is } \\
\text { required. If pathology is detected, assessment for } \\
\text { possible associated occult arrhythmia (with 24- } \\
\text { hour Holter monitoring) is strongly recommended. } \\
\text { Limitations on aircrew duties may be required while } \\
\text { under investigation }\end{array}$ & Strongly recommended \\
\hline $\begin{array}{l}\text { In aircrew with VHD in whom TTE imaging is } \\
\text { suboptimal, or when measurement of accurate } \\
\text { severity is challenging, CMR should be strongly } \\
\text { considered to assist with optimal assessment }\end{array}$ & Strongly recommended \\
\hline $\begin{array}{l}\text { In aircrew diagnosed with VHD, ambulatory cardiac } \\
\text { monitoring should be performed at diagnosis, and, } \\
\text { if potentially haemodynamically significant, at each } \\
\text { follow-up visit }\end{array}$ & Strongly recommended \\
\hline $\begin{array}{l}\text { In aircrew who have undergone surgery for } \\
\text { VHD, ambulatory cardiac monitoring should be } \\
\text { performed at } 6 \text { and } 12 \text { months post-surgery, and } \\
\text { then annually }\end{array}$ & Strongly recommended \\
\hline $\begin{array}{l}\text { Aircrew with VHD require long-term follow-up, } \\
\text { which must be at least as frequent as described } \\
\text { in national and international guidelines for } \\
\text { non-aircrew. More frequent follow-up should be } \\
\text { strongly considered when VHD is approaching } \\
\text { a severity which may require a change to flying } \\
\text { duties }\end{array}$ & Strongly recommended \\
\hline
\end{tabular}

\section{AORTIC VALVE DISEASE}

Aortic valve disease in the younger aircrew population is most commonly secondary to BAV disease. The prevalence of BAV is reported in $1 \%$ of the population ${ }^{14}$; it is associated with aortic stenosis, regurgitation, increased risk of endocarditis, aortic dilatation and aortic coarctation. The prevalence of aortic regurgitation in BAV is high, ${ }^{15-17}$ and significant aortic regurgitation (AR) and aortic stenosis (AS) both occur at a younger age than in those with tricuspid aortic valves. ${ }^{1718}$ Therefore, in aircrew with $\mathrm{BAV}$, there may be a greater likelihood of requiring intervention during their flying career. Surveillance of aircrew with BAV should therefore be at least as stringent as in those with morphologically normal aortic valves. BAV is also associated with higher rates of $\mathrm{IE},{ }^{1920}$ which is particularly relevant for military aircrew who may be required to operate in austere conditions. Genetic factors in BAV are widely recognised, and international guidance recommends TTE screening for BAV in those with a first-degree relative with $\mathrm{BAV}^{7}$ Whether or not to pursue such a screening policy in aircrew applicants remains a decision for individual agencies.

In older aircrew, the prevalence of degenerative disease increases and AS is the most common valve lesion requiring intervention. ${ }^{21} \mathrm{AR}$ is most commonly due to degenerative disease of either tricuspid or bicuspid aortic valves. ${ }^{21}$ Over time, haemodynamically significant regurgitation can result in volume overload of the left ventricle (LV), with consequent remodelling 
with eccentric hypertrophy, dilatation and systolic dysfunction. These features are associated with increased arrhythmic risk and decreased ability to increase forward stroke volume. Once AR is moderate in severity, it progresses faster than when mild, and bicuspid and degenerative disease are also associated with more rapid progression. ${ }^{22}{ }^{23}$ Regurgitant volume and LV volumes also provide useful information on likelihood of progression. ${ }^{24}$ Data on aircrew in the United States Air Force demonstrate significant rates of progression during follow-up ${ }^{25}$ with those with severe AR demonstrating annual event rates (symptoms, LV dysfunction or sudden death) of 3\%-6\%, ${ }^{26-28}$ which significantly exceeds the $1 \%$ threshold commonly used for multicrew operations in aviation. As aortic valve disease progresses, it may be associated with both atrial and ventricular dilatation and subsequent arrhythmia, so both the valve lesions and clinical sequelae are pertinent to risk assessment in the aviation environment.

\begin{tabular}{ll}
\hline Aortic valve disease & \\
\hline $\begin{array}{l}\text { Aircrew with any lesion greater than mild aortic } \\
\text { stenosis should be considered unfit for } \\
\text { high-performance and solo flying }\end{array}$ & Not recommended \\
\hline $\begin{array}{l}\text { Aircrew with moderate aortic regurgitation should be } \\
\text { carefully assessed and consideration given to multicrew } \\
\text { pilot roles only }\end{array}$ & Consider \\
$\begin{array}{l}\text { Aircrew with severe aortic stenosis, or severe } \\
\text { regurgitation, should be considered unfit for flying } \\
\text { duties }\end{array}$ & Not recommended \\
$\begin{array}{l}\text { In aircrew known to have aortic valve disease, } \\
\text { including BAV, national and international guidelines }\end{array}$ & Strongly recommended \\
for follow-up should be the minimum standard, \\
and more frequent follow-up may be required for \\
occupational reasons \\
$\begin{array}{l}\text { Aircrew with BAV should have comprehensive and } \\
\text { regular surveillance imaging of the thoracic aorta, as well }\end{array}$ Strongly recommended \\
$\begin{array}{l}\text { as valve surveillance, at least as frequently as recognised } \\
\text { guidelines recommend }\end{array}$ \\
$\begin{array}{l}\text { Aircrew with any degree of valvular stenosis who } \\
\text { have symptoms, arrhythmias, thromboembolic } \\
\text { disease, moderate or greater atrial dilatation, or } \\
\text { systolic dysfunction, should also be considered unfit } \\
\text { for flying duties }\end{array}$ \\
\hline
\end{tabular}

\section{MITRAL VALVE DISEASE}

Mitral regurgitation, secondary to valve prolapse, is the the most common form of VHD detected on population screening. ${ }^{29}{ }^{30} \mathrm{It}$ is most commonly a chronic degenerative process, and symptoms are present only with advanced disease or when arrhythmia supervenes. Over 5 years of follow-up, increasing severity of MR is seen in over a third of patients, ${ }^{31}$ while left atrial dilatation associated with MR increases risk of AF. AF is common with MR and is also associated with worse outcomes. ${ }^{32}$ Mitral stenosis is now uncommon in Western populations due to the decline of rheumatic fever. ${ }^{2130}$

The arrhythmic potential of mitral valve disease is a significant concern in aviation, driven by left atrial dilatation associated with both mitral stenosis and regurgitation. The potential for distraction or even incapacitation in aircrew with AF associated with mitral valve disease is an important consideration. AF also carries a thromboembolic risk which is increased in mitral valve disease, due to decreased forward flow and left atrial enlargement. The detection of AF, thromboembolism or significant atrial enlargement is therefore likely to be associated with additional restriction to flight duties beyond those which would be associated with the valve lesion alone.

\section{Mitral valve disease}

Aircrew with mitral stenosis, or moderate or greater mitral regurgitation should be considered unfit for high-performance flying

Aircrew with moderate mitral regurgitation should be carefully assessed and consideration given to multicrew pilot roles only

Aircrew with severe mitral regurgitation should be considered unfit flying duties

Aircrew with arrhythmia or systolic dysfunction associated with mitral valve disease should be considered unfit for flying duties

\section{TRICUSPID AND PULMONARY VALVE DISEASE}

Tricuspid valve disease is uncommon in aircrew; tricuspid regurgitation (TR) is more likely to be secondary or functional in aetiology than due to primary valve disease. Mild TR is an unremarkable finding in isolation, while haemodynamically significant TR gives rise to dilatation of the right atrium and right ventricle (RV) and may cause fatigue and dyspnoea; it is also associated with a significant risk of $\mathrm{AF}^{33}{ }^{34}$ The underlying aetiology of secondary TR is likely to dictate management of aircrew, rather than the TR itself. Although it may persist after intervention on associated left-sided valve lesions, ${ }^{35}$ the interventions themselves are likely to result in flying restrictions. When TR is the dominant feature, the risks associated with AF drives aircrew restrictions.

Tricuspid stenosis (TS) is rarely seen in Western countries, as it is most commonly rheumatic, congenital, associated with carcinoid or Whipple's disease, or treatment with ergot-like drugs. TS is associated with cardiac failure and fatigue and limits the ability to increase forward stroke volume. In rheumatic disease, TS is almost always associated with left-sided VHD, which tends to be more prominent. As a result, restrictions in aircrew are most likely to be dictated by associated valve lesions. When TS is due to other disease or drugs, the restrictions required by these are likely to require restrictions to flying duties.

Mild pulmonary regurgitation (PR) is considered a normal finding and does not require licensing restriction. Greater degrees of PR are associated with underlying conditions or may follow intervention for pulmonary stenosis (PS) or other congenital abnormalities. Aeromedical concerns in PR therefore relate to the underlying condition or to the potential for low cardiac output and arrhythmia with associated RV dysfunction.

PS is a common congenital abnormality in isolation but is also found in association with more complex defects, which are discussed elsewhere. ${ }^{36}$ Significant PS results in RV hypertrophy and is also associated with secondary TR. Mild and moderate PS have been shown to have long-term survival similar to those of the normal population ${ }^{37}$ and progression is rare; however, these increase the risk of arrhythmia, which is an important consideration in aircrew. Severe PS is likely to present in the neonatal period, requiring urgent assessment and management; this is unlikely to present in aircrew or applicants. However, if interventions have been undertaken as neonates, this will require specific consideration on licensing application.

As with aortic and mitral valve disease, aircrew with any pulmonary or tricuspid stenotic lesion greater than mild in severity should be deemed unfit for high-performance aircraft and unfit for solo flying. In moderate or severe tricuspid or PS, aircrew should be considered unfit for flying duties. In those 
with moderate regurgitation, they should be considered unfit for solo and high-performance flying, but may be considered for multicrew flying duties if the associated aetiology does not necessitate a more restrictive approach. In addition, the presence of symptoms, arrhythmias, thromboembolic disease, moderate or greater atrial dilatation, or systolic dysfunction should also indicate that aircrew should be grounded.

\begin{tabular}{ll}
\hline Tricuspid and pulmonary valve disease & \\
\hline $\begin{array}{l}\text { Aircrew with mild or greater tricuspid or pulmonary } \\
\text { stenosis, or moderate, or greater, tricuspid or pulmonary } \\
\text { regurgitation should be considered unfit for high- } \\
\text { performance flying }\end{array}$ & Not recommended \\
$\begin{array}{l}\text { Aircrew with moderate tricuspid or pulmonary } \\
\text { regurgitation should be carefully assessed and } \\
\text { consideration given to multicrew pilot roles only, } \\
\text { dependent on aetiology }\end{array}$ & Consider \\
\hline $\begin{array}{l}\text { Aircrew with severe tricuspid or pulmonary } \\
\text { regurgitation should be considered unfit for flying } \\
\text { duties }\end{array}$ & Not recommended \\
\hline $\begin{array}{l}\text { Aircrew with arrhythmia or systolic dysfunction associated } \\
\text { with mitral valve disease should be considered unfit } \\
\text { for flying duties }\end{array}$ & Not recommended \\
\hline
\end{tabular}

\section{AORTIC DISEASE}

Disease of the thoracic aorta, either with associated VHD or in isolation, requires careful consideration in the aircrew, particularly those who operate in the high-performance environment. Although the prevalence of aortic aneurysm is low before the age of 55, the increase in age of the aircrew population means it is likely to be seen more frequently in this group. Aortopathy associated with BAV is well recognised, and aortic aneurysms have been reported in up to $20 \%{ }^{1638}$; despite this, rates of dissection in BAV are very low under normal terrestrial conditions. ${ }^{16}$ However, in aircrew, concern arises about how the high-G environment might impact on underlying aortopathy. Exposure to rapid manoeuvring and high levels of $\mathrm{G}$, in any orientation, with the use of the anti-G straining manoeuvre has the potential to put additional mechanical stresses on the aorta, beyond those experienced in the terrestrial environment. Therefore, careful assessment and follow-up of the whole thoracic aorta is required, using recommended imaging modalities. ${ }^{739}$

The main concern with thoracic aortic aneurysms is the potential for dissection. The risk of dissection has been shown to increase more rapidly when the diameter of the ascending aorta is above $6 \mathrm{~cm} .{ }^{40}$ When aneurysm formation is associated with another condition, such as BAV or Marfan syndrome, the risk of dissection is higher; this mandates a more cautious aeromedical approach to these individuals. Although aortic dilatation may be associated with hypertension, or BAV, it can also be due to conditions such as Marfan syndrome, Loeys-Dietz or connective tissue disorder. Underlying conditions causing aortic dilatation are likely to have additional aeromedical ramifications beyond the heart, but also tend to have higher incidences of aortic dissection; thresholds for intervention may therefore be lower. Intervention for aortic aneurysms should be undertaken for the same indications as in standard clinical practice, although liaison between AME, surgeon and the aircrew member may assist in choosing a surgical technique most suited to the individual.

In those with a tricuspid aortic valve, and no associated underlying condition, recommended guidance for consideration of aircrew restriction (not surgical intervention) are laid out in table 2, and for those with a BAV in table 3.

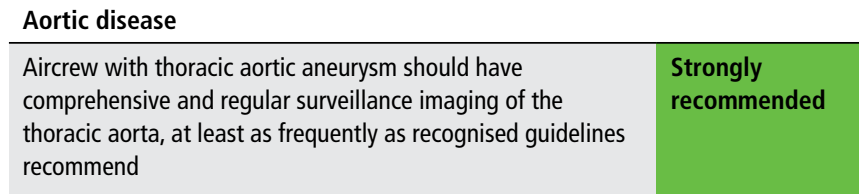

\section{CONCLUSION}

VHD represents a challenge to aviation medicine practitioners as rates of progression in milder forms of disease that may be relevant to aviation medicine, but of less clinical concern in the terrestrial environment, are variable and hard to predict due to paucity of evidence, and are often asymptomatic until late in the disease. Regular auscultation at aircrew examination is important for the potential detection of VHD. It requires careful long-term follow-up to ensure that aircrew can fly if it is safe and appropriate for them to do so, and to ensure that restrictions to flight duties are imposed when required. Stenotic valve disease, if more than mild, is of concern due to the potential risk of impaired $G_{z}$ tolerance, while moderate or greater regurgitation is associated with a greater risk of arrhythmia, which may result in distraction or even incapacitation; arrhythmia may also lower $G_{z}$ tolerance. Associated features of arrhythmia, systolic dysfunction, thromboembolism and chamber dilatation indicate additional risk, and will require more stringent restrictions. The use of appropriate cardiac imaging, along with routine ambulatory cardiac monitoring, is therefore mandatory in aircrew with VHD. A summary of recommendations can be found in table 4 .

Thoracic aortic aneurysm may be seen in isolation, or in association with bicuspid aortic valve disease. Progression rates are unpredictable, but as the diameter of the vessel increases, the associated risk of dissection also increases. Restrictions on aircrew duties, particularly in the context of high-performance or solo flying, are therefore likely to be required with progressive dilation of the aorta.

As with all cardiovascular conditions, intervention for VHD and aortic aneurysm should be in accordance with contemporary established guidelines and should not be undertaken for the purposes of affecting licensing requirement. A return to unrestricted flying following intervention for VHD or aortic disease is unlikely. Discussion of the anticipated impact of intervention

Table 2 Recommendations for aeromedical limitations for aortic dilatation in those with tricuspid aortic valves

\begin{tabular}{cll}
\hline $\begin{array}{l}\text { Aortic root diameter } \\
\text { (BSAID) }\left(\mathrm{cm} / \mathrm{m}^{2}\right)\end{array}$ & $\begin{array}{l}\text { Rate of change }(\mathrm{cm} / \\
\text { year })\end{array}$ & Aeromedical limitations \\
\hline$<4.5$ & $<0.5$ & $\begin{array}{l}\text { Unfit for high-performance } \\
\text { flying }\end{array}$ \\
$4.5-5.0$ & $<1$ & Unfit for solo flying \\
$>5.0$ & $>1$ & Unfit for flying duties \\
\hline
\end{tabular}

BSAID, body surface area indexed diameter, measured value $\times 1.73 / \mathrm{BSA}\left(\mathrm{m}^{2}\right)$.

Table 3 Recommendations for aeromedical limitations for aortic dilatation in those with bicuspid aortic valves

\begin{tabular}{cll}
\hline $\begin{array}{l}\text { Aortic root diameter } \\
\text { (BSAID) }\left(\mathrm{cm} / \mathrm{m}^{2}\right)\end{array}$ & $\begin{array}{l}\text { Rate of change }(\mathrm{cm} / \\
\text { year) }\end{array}$ & Aeromedical limitations \\
\hline$<4.25$ & $<0.5$ & $\begin{array}{l}\text { Unfit for high-performance } \\
\text { flying }\end{array}$ \\
$4.25-4.5$ & $0.5-1$ & Unfit for solo flying \\
$>4.5$ & $>1$ & Unfit for flying duties \\
\hline
\end{tabular}

BSAID, body surface area indexed diameter, measured value $\times 1.73 / \mathrm{BSA}\left(\mathrm{m}^{2}\right)$. 
Table 4 Summary table of the recommended restrictions for aircrew with valvular heart disease

\begin{tabular}{|c|c|c|c|c|}
\hline & $>$ Mild & Moderate & Severe & Additional considerations \\
\hline Aortic stenosis & $\begin{array}{l}\text { Unfit for high-performance } \\
\text { aircraft }\end{array}$ & Unfit for solo & Unfit & \\
\hline Aortic regurgitation & & $\begin{array}{l}\text { Unfit for high-performance aircraft } \\
\text { Unfit for solo }\end{array}$ & Unfit & \\
\hline Mitral stenosis & $\begin{array}{l}\text { Unfit for high-performance } \\
\text { aircraft } \\
\text { Unfit for solo }\end{array}$ & Unfit & Unfit & AF large atrium \\
\hline Mitral regurgitation & & $\begin{array}{l}\text { Unfit for high-performance aircraft } \\
\text { Unfit for solo }\end{array}$ & Unfit & \\
\hline Tricuspid stenosis & $\begin{array}{l}\text { Unfit for high-performance } \\
\text { aircraft } \\
\text { Unfit for solo }\end{array}$ & Unfit & Unfit & Arrhythmia, systolic dysfunction \\
\hline Tricuspid regurgitation & & $\begin{array}{l}\text { Unfit for high-performance aircraft } \\
\text { Unfit for solo }\end{array}$ & Unfit & Arrhythmia \\
\hline Pulmonary stenosis & $\begin{array}{l}\text { Unfit for high-performance } \\
\text { aircraft } \\
\text { Unfit for solo }\end{array}$ & Unfit & Unfit & Arrhythmia \\
\hline Pulmonary regurgitation & & $\begin{array}{l}\text { Unfit for high-performance aircraft } \\
\text { Unfit for solo }\end{array}$ & Unfit & $\begin{array}{l}\text { Arrhythmia, RV systolic } \\
\text { dysfunction }\end{array}$ \\
\hline
\end{tabular}

$\mathrm{AF}$, atrial fibrillation; RV, right ventricle.

on flying status may be helpful for the individual to understand prior to undergoing a procedure, but it should not be the dominant factor in deciding on timing or technique.

Contributors All authors are members of the NATO Occupational Cardiology WG and have contributed to the guidelines and production of this manuscript.

Funding Produced with support from NATO CSO and HFM-251 Partner Nations.

Competing interests None declared.

Patient consent Not required.

Provenance and peer review Commissioned; externally peer reviewed.

Open access This is an open access article distributed in accordance with the Creative Commons Attribution Non Commercial (CC BY-NC 4.0) license, which permits others to distribute, remix, adapt, build upon this work non-commercially, and license their derivative works on different terms, provided the original work is properly cited, appropriate credit is given, any changes made indicated, and the use is non-commercial. See: http://creativecommons.org/licenses/by-nc/4.0/.

\section{REFERENCES}

1 Nicol ED, Rienks R, Gray G, et al. An introduction to aviation cardiology. Heart. In Press. 2018

2 Mangione S, Nieman LZ. Cardiac auscultatory skills of internal medicine and family practice trainees. A comparison of diagnostic proficiency. JAMA 1997;278:717-22.

3 Roy D, Sargeant J, Gray J, et al. Helping family physicians improve their cardiac auscultation skills with an interactive CD-ROM. J Contin Educ Health Prof 2002;22:152-9.

4 Syburra T, Nicol E, Mitchell S, et al. To fly as a pilot after cardiac surgery. Eur J Cardiothorac Surg 2018;53:505-11.

5 Guettler N, Nicol ED, d'Arcy JL, et al. Pre- and post-cardiac surgical assessment and management of aircrew. Heart 2018. TBD.

6 Guettler N, Bron D, Manen O, et al. The management of cardiac conduction abnormalities and arrhythmia in aircrew. Heart 2018. TBD.

7 Baumgartner H, Falk V, Bax JJ, et al. 2017 ESC/EACTS Guidelines for the management of valvular heart disease. Eur Heart J 2017;38:2739-91.

8 Nishimura RA, Otto CM, Bonow RO, et al. 2017 AHA/ACC focused update of the 2014 AHA/ACC guideline for the management of patients with valvular heart disease: a report of the American College of Cardiology/American Heart Association task force on clinical practice guidelines. Circulation 2017;135:e115 9-e95.

9 Myerson SG, d'Arcy J, Mohiaddin R, et al. Aortic regurgitation quantification using cardiovascular magnetic resonance: association with clinical outcome. Circulation 2012;126:1452-60

10 Myerson SG, d'Arcy J, Christiansen JP, et al. Determination of clinical outcome in mitral regurgitation with cardiovascular magnetic resonance quantification. Circulation 2016;133:2287-96.
11 Shah AS, Chin CW, Vassiliou V, et al. Left ventricular hypertrophy with strain and aortic stenosis. Circulation 2014;130:1607-16.

12 Das $\mathrm{P}$, Rimington $\mathrm{H}$, Chambers J. Exercise testing to stratify risk in aortic stenosis. Eur Heart J 2005;26:1309-13.

13 Picano $E$, Pibarot $P$, Lancellotti $P$, et al. The emerging role of exercise testing and stress echocardiography in valvular heart disease. J Am Coll Cardiol 2009;54:2251-60.

14 Braverman AC, Güven H, Beardslee MA, et al. The bicuspid aortic valve. Curr Prob/ Cardiol 2005:30:470-522.

15 Michelena HI, Desjardins VA, Avierinos JF, et al. Natural history of asymptomatic patients with normally functioning or minimally dysfunctional bicuspid aortic valve in the community. Circulation 2008;117:2776-84.

16 Michelena HI, Khanna AD, Mahoney D, et al. Incidence of aortic complications in patients with bicuspid aortic valves. JAMA 2011;306:1104-12.

17 Masri A, Kalahasti V, Alkharabsheh S, et al. Characteristics and long-term outcomes of contemporary patients with bicuspid aortic valves. J Thorac Cardiovasc Surg 2016;151:1650-9.

18 Roberts WC, Ko JM, Jm K. Frequency by decades of unicuspid, bicuspid, and tricuspid aortic valves in adults having isolated aortic valve replacement for aortic stenosis, with or without associated aortic regurgitation. Circulation 2005;111:920-5.

19 Kong WK, Delgado V, Poh KK, et al. Prognostic implications of raphe in bicuspid aortic valve anatomy. JAMA Cardio/ 2017;2:285-92.

20 Rodrigues I, Agapito AF, de Sousa L, et al. Bicuspid aortic valve outcomes. Cardiol Young 2017:27:518-29.

21 lung $B$, Baron G, Butchart EG, et al. A prospective survey of patients with valvular heart disease in Europe: The Euro Heart Survey on Valvular Heart Disease. Eur Heart $J$ 2003;24:1231-43.

22 Padial LR, Oliver A, Vivaldi M, et al. Doppler echocardiographic assessment of progression of aortic regurgitation. Am J Cardiol 1997;80:306-14.

23 Vaturi $M$, Porter $A$, Adler $Y$, et al. The natural history of aortic valve disease after mitral valve surgery. J Am Coll Cardiol 1999;33:2003-8.

24 Kusunose K, Cremer PC, Tsutsui RS, et al. Regurgitant volume informs rate of progressive cardiac dysfunction in asymptomatic patients with chronic aortic or mitral regurgitation. JACC Cardiovasc Imaging 2015;8:14-23.

25 Davis SM, Davenport ED, Haynes JT, et al. Regurgitant valvular disease prevalence and progression found on echocardiogram in military aviators. Aviat Space Environ Med 2014;85:1013-8.

26 Siemienczuk D, Greenberg B, Morris C, et al. Chronic aortic insufficiency: factors associated with progression to aortic valve replacement. Ann Intern Med 1989;110:587-92.

27 Bonow RO, Lakatos E, Maron BJ, et al. Serial long-term assessment of the natural history of asymptomatic patients with chronic aortic regurgitation and normal left ventricular systolic function. Circulation 1991;84:1625-35.

28 Tornos MP, Olona M, Permanyer-Miralda G, et al. Clinical outcome of severe asymptomatic chronic aortic regurgitation: a long-term prospective follow-up study. Am Heart J 1995; 130:333-9.

29 Coffey S, d'Arcy JL, Loudon MA, et al. The OxVALVE population cohort study (OxVALVE-PCS)-population screening for undiagnosed valvular heart disease in the elderly: study design and objectives. Open Heart 2014;1:e000043-e. 
30 Nkomo VT, Gardin JM, Skelton TN, et al. Burden of valvular heart diseases: a population-based study. Lancet 2006;368:1005-11.

31 Avierinos JF, Detaint D, Messika-Zeitoun D, et al. Risk, determinants, and outcome implications of progression of mitral regurgitation after diagnosis of mitral valve prolapse in a single community. Am J Cardio/ 2008;101:662-7.

32 Grigioni F, Avierinos JF, Ling LH, et al. Atrial fibrillation complicating the course of degenerative mitral regurgitation: determinants and long-term outcome. J Am Coll Cardiol 2002;40:84-92.

33 Ong K, Yu G, Jue J. Prevalence and spectrum of conditions associated with severe tricuspid regurgitation. Echocardiography 2014;31:558-62.

34 Yiu KH, Chen Y, Liu JH, et al. Burden and contributing factors associated with tricuspid regurgitation: a hospital-based study. Hosp Pract 2017;45:1-6.

35 Porter A, Shapira Y, Wurzel M, et al. Tricuspid regurgitation late after mitral valve replacement: clinical and echocardiographic evaluation. J Heart Valve Dis $1999 ; 8: 57-62$.
36 Nicol ED, Manen O, Guettler N, et al. Congenital heart disease in aircrew: ocupational assessment and management. Heart 2018. TBD.

37 Hayes CJ, Gersony WM, Driscoll DJ, et al. Second natural history study of congenital heart defects. Results of treatment of patients with pulmonary valvar stenosis. Circulation 1993;87:128-37.

38 Tzemos N, Therrien J, Yip J, et al. Outcomes in adults with bicuspid aortic valves. JAMA 2008:300:1317-25.

39 Nishimura RA, Otto C. 2014 ACC/AHA valve guidelines: earlier intervention for chronic mitral regurgitation. Heart 2014;100:905-7.

40 Elefteriades JA. Natural history of thoracic aortic aneurysms: indications for surgery, and surgical versus nonsurgical risks. Ann Thorac Surg 2002;74:S1877-S1880.

41 Wood EH, Sutterer WF, MARSHALL HW, et al. Effect of headward and forward accelerations on the cardiovascular system. WADC Tech Rep United States Air Force Wright Air Dev Cent Day Ohio 1961;60-634:1-48. 